\title{
DESEMPENHO PRODUTIVO E CARACTERÍSTICAS DE CARCAÇA DAS PROGÊNIES DE TOUROS ABERDEEN ANGUS E BRAFORD ALIMENTADOS COM DIETA DE ALTO GRÃO
}

Murilo Ferreira Galliani, Lucca Drumond Penachin, Juliana Pampana Nicolau, Ana Claudia Ambiel Corral Camargo, Murillo Ceolla Stefano Pereira

Universidade do Oeste Paulista - UNOESTE, Faculdade de Ciências Agrárias, Presidente Prudente, SP. E-mail: murilogalliani@hotmail.com

\section{RESUMO}

Objetivo deste trabalho foi avaliar as progênies meio sangue de dois touros da raça Aberdeen Angus e dois touros da raça Braford entre si, e fazendo um comparativo entre as raças. Os animais foram submetidos a um regime de confinamento cuja dieta era de acordo com as exigência de ganho de peso para terminação e continha altas concentrações de milho ("dieta de alto grão"). No desenvolvimento do experimento, foram utilizados novilhos não castrados, sendo 63 novilhos meio sangue Aberdeen Angus e 32 novilhos meio sangue Braford. Após 174 dias de confinamento, os animais foram abatidos e avaliados os parâmetros de desempenho produtivo dos mesmos e acabamentos de carcaça. Considerando as progênies das raças Braford e Aberdeen Angus, o ganho de peso médio diário foi de 1,27 e 1,38 kg/animal/dia; a média do peso da carcaça quente foi de 257,84 e $273,34 \mathrm{~kg}$ e a média do peso vivo final foi de 466,53 e $487,83 \mathrm{~kg}$. A comparação do desempenho produtivo entre as progênies dos dois touros da raça Aberdeen Angus não obtiveram diferenças significativas. Nos touros da raça Braford, a progênie de um dos touros diferiu na variável rendimento de ganho de carcaça. Na comparação dos desempenhos produtivos entre as raças, foi constatada uma superioridade da progênie da raça Aberdeen Angus comparada com a da raça Braford. Em relação ao acabamento de carcaça e premiação não houve diferença entre as raças, ambas sendo premiadas.

Palavras-chave: bovino de corte; raças europeias; alto grão; confinamento.

\section{PRODUCTION PERFORMANCE AND HOUSING CHARACTERISTICS OF ABERDEEN ANGUS AND BRAFORD BULBS PROGENIES FEEDING WITH HIGH GRAIN DIET}

\begin{abstract}
The objective of this work was to evaluate progenies of two half-blood Aberdeen Angus bulls and two halfblood Braford bulls between themselves, and compare the breeds. The animals were submitted to a special diet, which contained high concentrations of corn. In the development of the experiment, steers weren't castrated, which was 63 Aberdeen Angus half-blood steers and 32 Braford half-blood steers were used. After 174 days confined, the animals were slaughtered and evaluated the parameters of their productive, performance and carcass finishes. Considering the progenies of the Braford and Aberdeen Angus breeds, the average daily weight gain was $1.27 \mathrm{~kg}$ and $1.38 \mathrm{~kg}$ / animal / day; The mean carcass weight was 257.84 and $273.34 \mathrm{~kg}$ and the mean live weight was 466.53 and $487.83 \mathrm{~kg}$. The comparison of productive performance among the progenies of the two Aberdeen Angus bulls did not show significant differences. In the Braford bulls, the progeny of one of the bulls differed in the variable gain of carcass yield. In the comparison of the productive performances between the breeds, a superiority of the Aberdeen Angus progeny was verified compared to the Braford breed. Regarding the finishing of carcass and awards, there was no difference between the races, both being awarded.
\end{abstract}

Keywords: beef cattle; european races; high grain; feedlot. 


\section{INTRODUÇÃO}

O Brasil vem se apresentando como uma potência do agronegócio no contexto mundial, devido aos fatores climáticos, territoriais e históricos. Segundo Relatório PIBAgro-Brasil, de dezembro de 2014, elaborado pelo Centro de Estudos Avançados em Economia Aplicada (CEPEA), a pecuária sustentou o crescimento do agronegócio em 2014 e o faturamento com a bovinocultura de corte cresceu $14,18 \%$ (CEPEA, 2015).

Sobre a eficiência na pecuária de corte, Restle e Vaz (2003) demonstraram que está relacionada à redução na idade de abate, potencial genético do animal e alimentação de qualidade. Referente às características, rendimento, cortes comerciais, peso e o acabamento da carcaça são as principais variáveis de interesse comercial para os frigoríficos (COSTA et al., 2002).

Atualmente, a prática de terminação de bovinos em sistema de confinamento tem aumentado de forma significativa (OLIVEIRA; MILLEN, 2014) devido ao nível de seguridade quando o objetivo é atingir determinados índices produtivos e ao maior controle da dieta e monitoramento da resposta animal.

Dentre as raças com grandes desempenhos produtivos e comumente confinados no período que antecede o abate para obtenção de um maior ganho de peso, estão as raças Braford e Aberdeen Angus. Segundo a United Braford Breeders Inc. (2011), a raça Braford nasceu do cruzamento de touros Hereford e vacas Brahman, sendo aproximadamente $5 / 8$ de Hereford e $3 / 8$ Brahman. A raça foi introduzida no Brasil na década de 80 , possui uma presença intensa nos Estados Unidos, Austrália e Argentina. Suas características marcantes são: precocidade, velocidade de ganho de peso e temperamento dócil. Os animais da raça Angus são de origem Britânica e se caracterizam por serem de porte mediano, precoces sob o aspecto reprodutivo, crescimento, terminação e com excelente qualidade de carne. O Angus foi introduzido no Sul do Brasil a partir do ano de 1906 (PICCOLI et al., 2013).

Restle et al. (1995) e Restle e Vaz (1999) mostraram que a heterose e o grupo genético afetam significativamente as características relacionadas com o desempenho de machos confinados.

Considerando o cenário atual e as características das raças Aberdeen Angus e Braford, neste estudo o objetivo foi avaliar o desempenho produtivo e as características de carcaça das progênies meio sangue de dois touros reprodutores da raça Aberdeen Angus e dois touros reprodutores da raça Bradford e comparar as raças entre si.

\section{MATERIAL E MÉTODOS}

\subsection{Local Experimental}

O estudo foi conduzido no município de Santa Rita do Pardo - MS - Brasil.

Foram utilizados 63 animais com oito meses de idade, não castrados filhos de vacas Nelore e touros Aberdeen Angus, peso médio inicial de 247,7 kg. E 32 animais com oito meses, não castrados, filhos de vacas Nelore e touros Braford peso médio inicial de $245,4 \mathrm{~kg}$.

\subsection{Manejo dos animais e arraçoamento}

Todos os animais foram submetidos ao mesmo fornecimento de dietas e tipo de manejo. O programa de recebimento dos animais foi da seguinte forma: todos foram pesados, tratados com anti-helmínticos, vacinados contra doenças virais e bacterianas (rota e coronavírus, tétano, botulismo e sete tipos de Clostridium spp.) com medicamentos da empresa "Pfizer Animal Health, New York, NY".

Os animais analisados foram alimentados com dieta de milho grão inteiro, $85 \%$ milho e $15 \%$ de núcleo proteico (pellet). Os valores nutricionais do milho são apresentados nas Tabelas 1 e 2 e do núcleo utilizado estão descritos na Tabela 3.

Tabela 1. Valores nutricionais da dieta experimental de grão inteiro (\%)

\begin{tabular}{cccccccccc}
\hline PB & PD & EE & FB & RM & Ca & P & NDT & LIS & TRIP \\
\hline 9,0 & 5,8 & 3,7 & 2,5 & 1,3 & 0,02 & 0,25 & 80 & 0,27 & 0,06 \\
\hline
\end{tabular}

$\mathrm{PB}=$ proteína bruta; $\mathrm{PD}=$ proteína digestível; $\mathrm{EE}=$ extrato etéreo; $\mathrm{FB}=-$ fibra bruta; $\mathrm{RM}=$ resíduo mineral; $\mathrm{Ca}=\mathrm{cálcio}$; $\mathrm{P}$ = fósforo; NDT = nutrientes digestivos totais; LIS = lisina; TRIP = triptofano.

Fonte: Adaptado de Ferrarine (2004, p. 10) 
Tabela 2. Composição química média do grão de milho amarelo (\%)

\begin{tabular}{llcccc}
\hline & Amido & Proteína & Lipídios & Açúcares & Cinzas \\
\hline Grão inteiro & 71,5 & 10,3 & 4,8 & 2,0 & 1,4 \\
\hline
\end{tabular}

Fonte: Adaptado de Ferrarini (2004, p. 9)

Tabela 3. Valores nutricionais e composição química do núcleo proteico

\begin{tabular}{lr}
\hline \multicolumn{1}{c}{ COMPOSIÇÃO } & QUANTIDADE \\
\hline Cálcio (Mín- Máx.) & $30,00-45,00 \mathrm{~g} / \mathrm{kg}$ \\
Fósforo (Mín.) & $7.610,00 \mathrm{mg} / \mathrm{kg}$ \\
Enxofre (Mín.) & $10,35 \mathrm{~g} / \mathrm{kg}$ \\
Sódio (Mín.) & $7.850,00 \mathrm{mg} / \mathrm{kg}$ \\
Zinco (Mín.) & $300,00 \mathrm{mg} / \mathrm{kg}$ \\
Manganês (Mín.) & $93,50 \mathrm{mg} / \mathrm{kg}$ \\
Cobre (Mín.) & $81,00 \mathrm{mg} / \mathrm{kg}$ \\
Cobalto (Mín) & $7,00 \mathrm{mg} / \mathrm{kg}$ \\
lodo (Mín.) & $7,15 \mathrm{mg} / \mathrm{kg}$ \\
Selênio (Mín.) & $1,37 \mathrm{mg} / \mathrm{kg}$ \\
Potássio (Mín.) & $11,00 \mathrm{~g} / \mathrm{kg}$ \\
Proteína Bruta (Mín.) & $360,00 \mathrm{~g} / \mathrm{kg}$ \\
NNP* Equiv. Proteína (Máx.) & $150,00 \mathrm{~g} / \mathrm{kg}$ \\
NDT** (Estimado) & $550,00 \mathrm{~g} / \mathrm{kg}$ \\
Fibra Bruta (Mín.) & $70,00 \mathrm{~g} / \mathrm{kg}$ \\
Matéria Mineral (Máx.) & $273,00 \mathrm{~g} / \mathrm{kg}$ \\
Extrato Etéreo (Mín.) & $27,00 \mathrm{~g} / \mathrm{kg}$ \\
Vitamina A & $11560 \mathrm{Ul} / \mathrm{kg}$ \\
Vitamina D & $3400 \mathrm{Ul} / \mathrm{kg}$ \\
Vitamina E & $57,80 \mathrm{Ul} / \mathrm{kg}$ \\
Salinomicina (Mín.) & $110,00 \mathrm{mg} / \mathrm{kg}$ \\
Virginiamicina (Mín.) & $229,50 \mathrm{mg} / \mathrm{kg}$ \\
\hline
\end{tabular}

${ }^{*} \mathrm{NNP}=$ nitrogênio não proteico; ${ }^{* *} \mathrm{NDT}=$ nutrientes digestivos totais.

Fonte: Adaptado de Cardoso (2012, p.49)

Durante o período de adaptação, correspondente a quatorze dias, foi fornecida uma dieta inicialmente de $1,0 \mathrm{~kg} /$ animal/dia e a cada três dias acrescentava-se $0,5 \mathrm{~kg}$ de alimento na dieta (Tabela 4).

Tabela 4. Relação entre o período da adaptação e a quantidade de alimento ofertado

\begin{tabular}{|c|c|}
\hline Período de adaptação & Quantidade de alimento/animal \\
\hline 10 ao 3o dia & $1,0 \mathrm{~kg}$ \\
\hline 40 ao 6o dia & $1,5 \mathrm{~kg}$ \\
\hline 70 ao 8 o dia & $2,0 \mathrm{~kg}$ \\
\hline 90 ao 10 o dia & $2,5 \mathrm{~kg}$ \\
\hline 11 o ao 12 ㅇa dia & $3,0 \mathrm{~kg}$ \\
\hline 13ㅇ ao 14임 & $3,5 \mathrm{~kg}$ \\
\hline
\end{tabular}

Depois da adaptação e antes de serem confinados, os animais foram pesados individualmente em balança digital. Ao ingressarem no confinamento, cuja dimensão é de 50 metros de comprimento e 30 metros de largura, os animais foram divididos em dois piquetes com água à vontade disponível em bebedouro cuja dimensão é de 1,5 metros de comprimento por 1 metro de largura, estrategicamente posicionado entre os dois piquetes.

Foi ofertada uma dieta de $4 \mathrm{~kg}$ de ração/animal/dia durante sete dias. Com o passar deste período, acrescentava-se $0,3 \mathrm{~kg}$ de ração a cada três dias até chegar à quantidade de 10 $\mathrm{kg} / \mathrm{ração/animal} /$ dia. O período correspondente ao crescimento gradativo da oferta de ração foi 
de 67 dias, após a estabilização da dieta os animais mantiveram a mesma quantidade ingerida por dia até o dia do embarque. Os animais ficaram confinados, durante 174 dias.

O arraçoamento foi realizado quatro vezes ao dia: às $07 \mathrm{~h} 30 \mathrm{~min}$ ( $25 \%$ do total), às $11 \mathrm{~h} 30 \mathrm{~min}$ ( $25 \%$ do total), às $14 \mathrm{~h} 30 \mathrm{~min}$ ( $25 \%$ do total) e às $18 \mathrm{~h} 00 \mathrm{~min}$ ( $25 \%$ do total).

\subsection{Desempenho Produtivo}

Os indicadores econômicos analisados no estudo estão descritos abaixo:

*Ganho de Peso Diário (GPD): Avalia a quantidade de quilos que o animal ganha por dia. Sua fórmula se constitui pelo seguinte cálculo: peso do animal ao abate (em quilos) subtraído do peso do animal no início do experimento (em quilos) e o resultado dividido pelo período experimental (em dias):

$$
G P D(k g)=\frac{P V F-P V I}{P E X}
$$

$\mathrm{GPD}=$ ganho de peso diário $(\mathrm{kg}) ; \mathrm{PVF}=$ peso vivo final $(\mathrm{kg}) ; \mathrm{PVI}=$ peso vivo do início do confinamento $(\mathrm{kg}) ; \mathrm{PEX}=$ período experimental (dias).

*Peso de Carcaça Quente: Verificado mediante pesagem da carcaça quente (em quilos), entendendo-se como carcaça: o animal abatido, sangrado, esfolado, eviscerado, desprovido de cabeça (separada entre os ossos occipital e atlas), patas (seccionadas à altura das articulações carpo-metacarpiana e tarsometatarsiana), rabada, órgãos genitais externos, gordura perineal e inguinal, ferida de sangria, medula espinhal, diafragma e seus pilares.

*Rendimento de Carcaça (em porcentagem): Resultado da divisão do peso da carcaça quente (obtido no frigorífico), pelo peso do animal vivo (também denominado como "peso vivo", obtido na propriedade):

$$
\mathrm{RC}(\%)=\frac{P C Q}{P V F}
$$

$\mathrm{RC}=$ rendimento de carcaça (\%); $\mathrm{PCQ}=$ peso de carcaça quente $(\mathrm{kg}) ; \mathrm{PVF}=$ peso vivo final (kg).

*Rendimento de Ganho de Carcaça (\%): O rendimento de carcaça é definido como a relação entre o peso da carcaça e o peso do animal vivo, expresso em porcentagem.

$$
\mathrm{RGC}(\%)=\frac{(\mathrm{PCQ}-\mathrm{PVI} * 0,5)}{\mathrm{PVF}-\mathrm{PVI}}
$$

RGC (\%)= rendimento de ganho de carcaça; $\mathrm{PCQ}=$ peso de carcaça quente (kg); $\mathrm{PVI}=$ peso vivo do início do confinamento (kg); PVF: peso vivo final $(\mathrm{kg})$.

*Ganho Líquido de Carcaça Diário (quilos): é o ganho de peso no período do confinamento multiplicado pelo rendimento de ganho de carcaça.

$$
G L C D(k g)=G P P C * R G C
$$

$\operatorname{GLCD}(\mathrm{kg})$ = ganho líquido de carcaça diário; GPPC $(\mathrm{kg})=$ ganho de peso no período do confinamento; RGC (\%) = rendimento de ganho de carcaça.

\subsection{Classificações de acabamento de carcaça}

*Classificação de Acabamento de Carcaça: Verificada mediante observação da distribuição e quantidade de gordura de cobertura, em locais diferentes da carcaça (à altura das 6a 9 a e 12 a costelas, nas partes dorsal e ventral do músculo grande dorsal e músculo serrátil dorsal caudal, na região lombar e no coxão), estabelecendo-se as seguintes categorias: Magra (1): gordura ausente; Gordura escassa (2): 1 a $3 \mathrm{~mm}$ de espessura; Gordura mediana (3): acima de 3 e até $6 \mathrm{~mm}$ de espessura; Gordura uniforme (4): acima de 6 e até $10 \mathrm{~mm}$ de espessura; Gordura excessiva (5): acima de 10 $\mathrm{mm}$ de espessura.

*Premiação: Conforme o acordo feito entre frigorífico e pecuarista, ocorre uma premiação financeira ao segundo quando carcaças de bovinos vendidos por este atendem a requisitos como, por exemplo, melhor cobertura de gordura.

\subsection{Delineamentos experimentais e análise estatística}

O delineamento experimental foi inteiramente casualizado e os piquetes foram considerados as unidades experimentais para todas as variáveis deste estudo. Foram realizados testes de normalidade dos resíduos e de heterogeneidade de variâncias antes de se proceder a análise de variância, e quando necessário, os dados foram transformados.

Todos os dados do experimento foram analisados utilizando-se o PROC GLM do SAS (2003), considerando o nível de $5 \%$ de significância de acordo com o modelo:

$$
Y_{i j}=\mu+T_{i}+e_{i j} ;
$$


$\mathrm{Y}_{\mathrm{ij}}=$ observação relativa à jésima unidade experimental (piquete) do $i^{\text {ésimo }}$ tratamento; $\mu=$ média geral; $T_{i}=$ efeito do $i^{\text {ésimo }}$ tratamento, sendo $\mathrm{i}=$ Curve Bender, Dimension; Taragui, Duque; Angus e Bradford; $e_{i j}=$ erro experimental referente à $j^{\text {ésima }}$ unidade experimental do $i^{\text {ésimo }}$ tratamento $\left(0 ; \sigma_{e}^{2}\right)$.

As variáveis de acabamento de carcaça e bonificação foram analisadas pelo teste QuiQuadrado.

\section{RESULTADOS E DISCUSSÃO}

Os resultados das análises estatísticas referentes às comparações das progênies dos touros de mesma raça e dos touros entre as raças (Aberdeen Angus e Braford) estão apresentados nas Tabelas 5 a 10.

De acordo com os resultados obtidos, não houve diferença estatística significativa da progênie dos touros Aberdeen Angus no que diz respeito ao desempenho produtivo e às características das carcaças (Tabela 5). O mesmo verifica-se na Tabela 6, não havendo diferença entre progênies, em relação à classificação de acabamento de carcaça e premiação do frigorífico.

Tabela 5. Desempenho produtivo e características de carcaça das progênies de dois touros da raça Aberdeen Angus alimentados com dieta de milho grão inteiro.

\section{Touros Aberdeen Angus}

Curve Bender Dimension

Variáveis

\section{Coeficiente de Variação Valor de $p$ (C.V.)}

\begin{tabular}{lcccc}
\hline Peso vivo inicial $(\mathrm{kg})$ & 245,89 & 249,29 & 8,97 & 0,55 \\
Peso vivo final $(\mathrm{kg})$ & 485,14 & 489,97 & 6,42 & 0,55 \\
Ganho de peso diário $(\mathrm{kg})$ & 1,38 & 1,38 & 8,79 & 0,79 \\
Peso de carcaça quente $(\mathrm{kg})$ & 271,25 & 275,01 & 7,71 & 0,55 \\
Rendimento de carcaça $(\%)$ & 55,91 & 56,10 & 3,55 & 0,70 \\
Rendimento de ganho de carcaça $(\%)$ & 62,03 & 62,39 & 6,49 & 0,72 \\
Ganho líquido de carcaça diário $(\mathrm{kg})$ & 0,852 & 0,864 & 11,25 & 0,64 \\
\hline
\end{tabular}

Médias $(p<0,05)$ diferem entre si nas linhas.

Tabela 6. Classificação de acabamento de carcaça e premiação das progênies de dois touros da raça Aberdeen Angus, alimentados com dieta de milho grão inteiro.

\begin{tabular}{lccc}
\hline \multirow{2}{*}{ Variáveis } & \multicolumn{2}{c}{ Touros Aberdeen Angus } & \multirow{2}{*}{ Valor de $p$} \\
\hline Classificação de acabamento de carcaça & Curve Bender & Dimension & \\
Premiação & Mediano & Mediano & 0,33 \\
\hline
\end{tabular}

Médias $(p<0,05)$ diferem entre si nas linhas.

Analisando a Tabela 7, observamos que a progênie do touro Duque obteve maior rendimento de ganho de carcaça $(P<0,05)$, com $63,03 \%$, que a progênie do touro Taragui, que apresentou um rendimento de ganho de carcaça de $58,76 \%$. Estes resultados das progênies dos touros Duque e Taragui, abatidas com 16 meses, são superiores ao resultado encontrado no estudo desenvolvido por Restle (1999b), onde foi evidenciado o rendimento de carcaça de touros da raça Braford de 54,7\%, abatidos aos 14 meses de idade. Tal diferença entre os rendimentos pode ser explicada pelo maior tempo de vida dos animais deste estudo ou pelo alto índice energético de sua ração. Proskuryakov et al. (1982), também estudando animais da raça Braford, desmamados com 120, 150, 180 e 210 dias e abatidos aos 18 meses, avaliaram o efeito da idade ao desmame sobre o rendimento de carcaça, encontrando os valores de $54,2 \%, 54,0 \%$, $53,6 \%$ e $53,9 \%$, respectivamente. Comparando com os animais da raça Braford utilizados neste estudo (desmamados entre 210 e 240 dias e abatidos com 16 meses) verificamos um maior desempenho produtivo destes animais, mesmo abatidos com menor tempo de vida, que os animais estudados por Proskuryakov (1982). Este maior desempenho pode ter sido influenciado 
pelo alto índice energético da ração oferecida aos

animais deste estudo.

Tabela 7. Desempenho produtivo e características de carcaça das progênies de dois touros da raça Braford alimentados com dieta de milho grão inteiro.

\begin{tabular}{lcccc}
\hline \hline \multicolumn{1}{c}{ Variáveis } & \multicolumn{2}{c}{ Touros Braford } & \multicolumn{2}{c}{ Coeficiente } \\
de Variação & Valor de $p$ \\
& Taragui & Duque & (C.V.) & \\
\hline Peso vivo inicial $(\mathrm{kg})$ & 240,77 & 248,68 & 9,79 & 0,36 \\
Peso vivo final $(\mathrm{kg})$ & 465,31 & 460,53 & 7,78 & 0,24 \\
Ganho de peso diário (kg) & 1,30 & 1,22 & 10,03 & 0,38 \\
Peso de carcaça quente (kg) & 257,82 & 257,85 & 8,22 & 0,24 \\
Rendimento de carcaça (\%) & 54,28 & 55,28 & 3,94 & 0,30 \\
Rendimento de ganho de carcaça (\%) & 58,76 & 63,03 & 7,62 & 0,01 \\
Ganho líquido de carcaça diário $(\mathrm{kg})$ & 0,789 & 0,767 & 11,68 & 0,49 \\
\hline
\end{tabular}

Médias $(p<0,05)$ diferem entre si nas linhas.

Não foram observadas diferenças entre as progênies dos touros, quando comparados à classificação do acabamento de carcaça e premiação (Tabela 8).

Tabela 8. Classificação de acabamento de carcaça e premiação das progênies de dois touros da raça Braford, alimentados com dieta de milho grão inteiro.

\begin{tabular}{lccc}
\hline \multicolumn{1}{c}{ Variáveis } & \multicolumn{2}{c}{ Touros Braford } & \multirow{2}{*}{ Valor de $p$} \\
\hline Classificação de acabamento de carcaça & Taragui & Duque & \\
Premiação & Apenas @ & Mediano & 0,08 \\
\hline
\end{tabular}

Médias $(p<0,05)$ diferem entre si nas linhas.

Na comparação entre as raças Aberdeen Angus e Braford, observou-se que a progênie dos touros da raça Aberdeen Angus obtiveram maior ganho de peso diário e maior ganho líquido diário. Os resultados apresentados neste estudo mostraram que os animais da raça Aberdeen
Angus são mais precoces, justificados pelo maior ganho de peso vivo e da carcaça ao abate (Tabela 9), em relação aos animais da raça Braford, no mesmo período de confinamento com dieta de alto grão.

Tabela 9. Desempenho produtivo e características de carcaça de bovinos da raça Aberdeen Angus e bovinos da raça Braford alimentados com dieta de milho grão inteiro.

\begin{tabular}{lcccc}
\hline \multicolumn{1}{c}{ Variáveis } & $\begin{array}{c}\text { Raças } \\
\text { Aberdeen } \\
\text { Angus }\end{array}$ & Braford & $\begin{array}{c}\text { Coeficiente } \\
\text { de Variação } \\
\text { (C.V.) }\end{array}$ & Valor de $p$ \\
\hline Peso vivo inicial $(\mathrm{kg})$ & 247,78 & 245,47 & 9,19 & 0,64 \\
Peso vivo final $(\mathrm{kg})$ & 487,83 & 466,53 & 6,87 & $<0,01$ \\
Ganho de peso diário $(\mathrm{kg})$ & 1,38 & 1,27 & 9,96 & $<0,01$ \\
Peso de carcaça quente $(\mathrm{kg})$ & 273,34 & 257,84 & 7,82 & $<0,01$ \\
Rendimento de carcaça (\%) & 56,01 & 55,29 & 3,83 & 0,10 \\
Rendimento de ganho de carcaça (\%) & 62,23 & 61,30 & 7,26 & 0,33 \\
Ganho líquido de carcaça diário $(\mathrm{kg})$ & 0,858 & 0,776 & 11,35 & $<0,01$ \\
\hline
\end{tabular}

Médias $(p<0,05)$ diferem entre si nas linhas.

Em relação à média do peso vivo final, os valores médios obtidos pela raça Aberdeen Angus foram de 487,83 quilos, enquanto que os animais da raça Braford pesaram, em média, 466,53 quilos, obtendo, assim, uma vantagem da raça Aberdeen Angus sobre a raça Braford, de 21,3 quilos por carcaça. A precocidade da raça Aberdeen Angus é afirmada pela Associação 
Brasileira de Angus [201-?], a qual descreve que a raça, em comparação com outras raças, tem demonstrado que, nas mesmas condições alimentares, atinge mais cedo o estado de abate e, também, pela ANGUS PORTUGAL [201-?], afirmando que a raça, além da precocidade, apresenta uma boa acumulação e distribuição de gordura do tecido intramuscular, entre outras características.

Um experimento de Costa et al. (2002), demonstrou que novilhos Aberdeen Angus, com um ano de idade, peso inicial de 338 quilos, abatidos com pesos médios de 361, 388, 416 e 437 quilos, após um período de alimentação de $28,56,84$ e 112 dias, com concentrado de 1,5\% do peso vivo e silagem de milho, obtiveram um ganho médio diário de 0,$734 ; 0,706 ; 0,613$ e 0,514 quilos, respectivamente. No presente estudo, o peso vivo inicial dos animais da raça Aberdeen Angus foi de 247,78 quilos, peso vivo final 487,83 quilos, após 188 dias confinados com dieta de alto grão ( $85 \%$ milho $+15 \%$ pellet), obtendo o ganho médio diário de 1,38 quilos. Desta forma, comparando o presente estudo e o de Costa et al., mesmo havendo diferença na dieta podemos afirmar que a dieta de alto grão utilizada neste experimento foi mais eficiente em termos de ganho médio diário que o estudo de Costa et al. (2002). Segundo Arrigoni et al. (2004), vários trabalhos sobre o desempenho de bovinos cruzados, oriundos de zebuínos e europeus, demonstraram maior taxa de crescimento e melhor aproveitamento dos alimentos em animais com maior percentagem de sangue europeu, principalmente ao se utilizar bovinos da raça Aberdeen Angus. Para Zamboni (2010), o grau de sangue Aberdeen Angus influencia significativamente 0 grau de acabamento de carcaça. Em seu estudo, a média dos escores visuais atribuídos às carcaças dos animais $1 / 2$ sangue Aberdeen Angus foi superior à dos animais $3 / 4$ Nelore e dos animais Nelores puros, sendo que a média dos animais $3 / 4$ Nelore foi maior que a dos Nelores puros, demonstrando que a raça Aberdeen Angus tem influência positiva sobre esse quesito. Além disso, a carne de bovinos Aberdeen Angus também se apresenta mais macia, como relatado no estudo de Pereira et al. (2009), que, comparando a textura da carne de novilhos Nelore e $1 / 2$ Aberdeen Angus $X$ Nelore superprecoces, reportaram que a carne dos animais cruzados.

Já na comparação das raças, quando avaliadas a classificação de acabamento de carcaça e a premiação pelo frigorífico, nenhuma raça teve vantagem sobre a outra, conforme observado na Tabela 10, mas ambas as progênies receberam premiação financeira pelo frigorífico.

Tabela 10. Classificação de acabamento de carcaça e premiação de bovinos da raça Aberdeen Angus e bovinos da raça Braford alimentados com dieta de milho grão inteiro.

\begin{tabular}{lccc}
\hline \multirow{2}{*}{ Variáveis } & Raças & \multirow{2}{*}{ Valor de $p$} \\
\hline Classificação de acabamento de carcaça & Aberdeen Angus & Braford & \\
Premiação & Mediano & Mediano & 0,54 \\
\hline
\end{tabular}

Médias $(p<0,05)$ diferem entre si nas linhas.

\section{CONCLUSÃO}

Concluímos que a comparação do desempenho produtivo entre as progênies dos dois touros da raça Aberdeen Angus não obtiveram diferenças significativas. Entre os dois touros da raça Braford, a progênie do touro Duque obteve maior rendimento de ganho de carcaça quando comparado à progênie do touro Taragui.

$\mathrm{Na}$ comparação entre raças, foi constatada uma superioridade da progênie da raça Aberdeen Angus comparada com a da raça Braford, em relação aos desempenhos produtivos que são: peso vivo final, ganho de peso diário, peso de carcaça quente e ganho líquido de carcaça diário. Em relação ao acabamento de carcaça e premiação, não houve diferença entre as raças, ambas sendo premiadas.

\section{REFERÊNCIAS}

ANGUS PORTUGAL - Roland Winter. Aberdeen

Angus: raça. [200-?]. Disponível em:

$<$ http://www.angus.com.pt/raca.html $>$. Acesso em: 15 maio 2015.

ARRIGONI, M. B.; ALVES JÚNIOR, A.; DIAS, P.M.A.; LUDOVICO, C.; CERVIERI, R. da C.; SILVEIRA, A.C.; OLIVEIRA, H.N.; CHARDULO, L.A.L. Desempenho, fibras musculares e carne de bovinos jovens de três grupos genéticos. Pesquisa Agropecuária 
Brasileira, v.39, p.1033-1039, 2004.

https://doi.org/10.1590/S0100-

$\underline{204 \times 2004001000012}$

ASSOCIAÇÃO BRASILEIRA DE ANGUS. Raça:

características - precocidade. [200-?]. Disponível em: <http://angus.org.br/raca/caracteristicas/>. Acesso em: 15 maio. 2015.

CARDOSO, E. O. Dieta de alto grão para bovinos confinados: viabilidade econômica e qualidade da carne. 2012. 66f. Dissertação (Mestrado) Universidade Estadual do Sudoeste da Bahia, 2012.

CEPEA. Relatório PIB-Agro Brasil. 2014.

Disponível em:

<http://www.cepea.esalq.usp.br/comunicacao/C epea_PIB_BR_dez14.pdf>. Acesso em: 19 abr.. 2015.

COSTA, E.C.; RESTLE, J.; VAZ, F.N; ALVES FILHO,. D.C.; BRENARDES, R.A.L.C.; KUSS, F.

Características da carcaça de novilhos Red Angus superprecoces abatidos com diferentes pesos.

Revista Brasileira de Zootecnia, v.31, n.1, p.119128, 2002a. https://doi.org/10.1590/S1516$\underline{35982002000100014}$

DIAS FILHO, A. Técnicas aplicadas para o confinamento de bovinos. Brasília: UnB, 2011.

FERRARINI, H. Determinação de teores nutricionais do milho por espectroscopia no infravermelho e calibração multivariada. 2004. Tese (Doutorado) - Universidade Federal do Paraná. Curitiba-PR, 2004.

OLIVEIRA, C. A.; MILLEN, D. D. Survey of the nutritional recommendations and management practices adopted by feedlot cattle nutritionists in Brazil. Animal Feed Science and Technology, v. 197, p. 64-75, 2014.

https://doi.org/10.1016/j.anifeedsci.2014.08.010

PEREIRA, P.M.R.C.; PINTO, M.F.; ABREU, U.G.P.; LARA, J.A.F. Características de carcaça e qualidade de carne de novilhos superprecoces de três grupos genéticos. Pesquisa Agropecuária Brasileira, v.44, n.11, p.1520-1527, 2009. https://doi.org/10.1590/S0100$\underline{204 \times 2009001100021}$
PEROTTO, D.; MOLETTA, J.L.; OLIVEIRA, J. E. P.; LESSKIU, C. Consumo e conversão alimentar de machos bovinos inteiros Charolês, Caracu e cruzamentos recíprocos em confinamento.

Revista Brasileira de Zootecnia, Viçosa, v. 29, n. 1, p. 108-116, fev. 2000. Disponível em:

$<$ http://www.scielo.br/scielo.php?script=sci_artt ext\&pid=S1516-

$35982000000100015 \& \operatorname{lng}=e n \& n r m=i s o>$. Acesso em: 22 maio 2015.

PICCOLI, M. L.; BRACCINI NETO, J.; BERTOLI, C. D.; COBUCl, J. A.; CAMPOS, G. S.; GAMA, L. T.

Estrutura populacional da raça Angus criada no Brasil. In: SIMPÓSIO BRASILEIRO DE

MELHORAMENTO ANIMAL, 10. 2013, Uberaba.

Anais... Uberaba, 2013.

PROSKURYAKOV, A.; IBRAGIMOV, U.; KHARITONOVA, $S$. Weaning age of young beef cattle during intensive rearing. Molochnoe $\mathbf{i}$ Myasnoe Skotovodstvo, Moscou, n.9, p.29-30, Sept. 1982.

RESTLE, J.; BRONDANI, I.L.; BERNARDES, R.A.C. O novilho superprecoce. In: RESTLE, J.

(Ed.). Confinamento, pastagens e suplementação para produção de bovinos de corte. Santa Maria: Universidade Federal de Santa Maria, 1999a. p.191-214.

RESTLE, J., FELTEN, H.G., VAZ, F.N. Efeito de raça e heterose para desempenho em confinamento de novilhos de corte. In: REUNIÓN LATINOAMERICANA DE PRODUCCIÓN ANIMAL, 14, 1995, Mar del Plata. Memorias... Balcarce: ALPA, 1995. v.3-4, p.852-854.

RESTLE, J.; VAZ, F. Confinamento de Bovinos definidos e cruzados. In: LOBATO, J.F.P., BARCELLOS, J.O.J.,KESSLER, A.M. (Eds.) Produção de bovinos de corte. Porto Alegre: EDIPUCRS, 1999. p.141-168.

RESTLE, J.; VAZ, F.N. Eficiência e qualidade na produção de carne bovina. In: REUNIÃO ANUAL DA SOCIEDADE BRASILEIRA DE ZOOTECNIA, 40, 2003, Santa Maria. Anais... Santa Maria: SBZ, [2003]. 34p., CD-ROM.

SAS INSTITUTE INCORPORATION. SAS Version 9.1. Cary, 2003. 7857p. 
ZAMBONI, V. T. Correlação entre escores visuais de conformação e indicadores de desempenho, características de carcaça e de carne de novilhos nelore e cruzados aberdeen angus $\mathrm{x}$ nelore. 2010. 44 f. Dissertação (Mestrado) - Medicina Veterinária Preventiva e Produção Animal da Unesp, Araçatuba-SP, 2010.

Recebido para publicação em 10/08/2017

Revisado em28/11/2017

Aceito em 05/02/2018 